\title{
Endorphins on Cancer: A Novel Therapeutic Approach
}

\section{Shrihari TG*}

Department of Oral Medicine and Oral Oncology, Krishna Devaraya College of Dental Sciences and Hospital, Bangalore-562157, Karnataka, India

*Corresponding author: Shrihari TG, Department of Oral Medicine and Oral Oncology, Krishna Devaraya College of Dental Sciences and Hospital, Bangalore-562157, Karnataka, India, Tel: +919844386188; E-mail: drshrihariomr@gmail.com

Received date: May 13, 2017; Accepted date: July 19, 2017; Published date: July 24, 2017

Copyright: @ 2017 Shrihari TG. This is an open-access article distributed under the terms of the Creative Commons Attribution License, which permits unrestricted use, distribution, and reproduction in any medium, provided the original author and source are credited.

\begin{abstract}
Endorphins are natural neuropeptides secreted by anterior pituitary gland through hypothalamus in response to stress full conditions such as physical exercise, yoga and meditation. Stress is also a one of the predisposing factor for cancer by activating inflammatory mediators such as IL-1 and TNF- $\alpha$, involved in tumor progression. It has stress buster activity by reducing cortisol, analgesic activity by inhibiting substance $P$, euphoric activity by releasing dopamine and immune-stimulatory activity by activating NK cells, macrophages. It can be used for natural antitumor activity by activating NK cells, macrophage innate immune cells, and has anti-inflammatory activity by inducing IL-12, IL-8 cytokines. It has got it's receptors on the immune cells, binding of endogenous opioids such as beta endorphin to the receptors on the immune cells, activates immune cells. This article briefs about the role of Beta endorphin on cancers and its anticancer activities.
\end{abstract}

Keywords: IL-1 Beta; IL-6; TNF- $\alpha$; Stress; Cortisol; Meditation

\section{Introduction}

Cancer is a major threat in the present world. Many advanced cancer treatment modalities such as surgery, chemotherapy and radiotherapy fail to improve the prognosis, which is about 50 percent for 5 year survival rate with increasing morbidity and mortality. Cancer cells work like normal cells, I don't know, how to kill the cancer cells without killing normal cells (Albert Szent-Gyorgyi).

The present concept of whole body healing rather than healing a part of the body yields better results. Human body has its own mechanism to heal by the factors secreted by our own body. Cancer is mainly due to external environmental factors such as tobacco consumption in the form of chewable or non-chewable form, alcohol consumption lead to oral squamous cell carcinoma, chemical ingestion leading to lung cancer, altered dietary habits leading to colon cancer, hepatocellular cancer. Leukemia's are due to chemical ingestions, HPV induced oropharyngeal carcinoma and cervical cancer. Endorphins are endogenous morphins responsible for relaxed psychological state creation known as "runner's high" [1-14].

\section{Role of Stress in Cancer}

Endogenous opioids are neurotransmitter secreted and synthesized by anterior pituitary; receptors are present in brain and on immune cells. Neuroendocrinal pathway connects between nervous system, endocrinal system and immune cells in our body. Neuroendocrinal flow, which connects central nervous system to peripheral nervous system via hypothalamic pituitary axis (HPA) and autonomic nervous system (ANS) through direct nerve fibre connections with cells or the organs of the immune system [3]. Psychological stress is also a very important etiological factor for cancer by releasing cortisol, catacholomines, neuropeptides mediated inflammatory changes such as release of IL-1 $\beta$, TNF- $\alpha$ protumorigenic cytokines, decreased expression of IL-2 and IFN- $\Upsilon$ leads to tumor progression by activating key transcriptional factor NF-KB [2-41].
Stress induced production of cortisol, epinephrine and norepinephrine results in upregulation of DNA damage sensors such as CHK1, CHK2 and proto-oncogene CDC25A results in DNA damage mediated delay in cell cycle, cell transformation or tumorigenicity. Catacholamines may promote cancer cell attachments, norepinephrine and epinephrine promote migration and invasive potential of ovarian cancer cells by increasing MmP-2,9 important for tumor invasion. Stress hormones including norepinephrine promote tumor progression, angiogenesis by production of IL-6, VEGF activates STAT3 transcriptional factor involved in cell proliferation and cell survival $[3,10,11]$. Chronic stress affects recruitment of neutrophils, NK, macrophages, APCs, T and B lymphocytes. It also modulates cell mediated immunity by suppressing NK cell activation, lymphocyte proliferation, CD4 $\mathrm{T}$ cells in peripheral blood and CD4/CD8 $\mathrm{T}$ cell ratio alteration. TNF- $\alpha$ inhibit the tyrosine phosphatase protein activity, leads to reduced production of MHC class 1 antigen of the cell surface results in tumor immune evasion. Evidences suggest that neuroendocrinal system and ANS connects from CNS to the immune system. Studies have shown that stress and depression might have indirect effect on carcinogenesis by decreased NK cell activity results in reduced elimination or destruction of abnormal cells associated with tumor growth and progression of variety of cancers in animals and humans. NK cells are only natural innate immune cells acts as first line of defense against tumor cells and their metastatic spread. Clinical trial on in vitro transgenic, knock out model suggested stress response leads to tumor suppressor genes down regulation such as PTEN (Phosphatase and tensin homolog) or BRCA1, DNA repair genes [3-7,9-13].

\section{Mechanism of Action of Beta Endorphins on Stress and Immune Cells}

Endogenous opioid includes endorphins, enkephalins and dynorphins, operate via $\mu$-opioid receptor bring about various changes such as analgesia, dopamine release in the brain is a stress buster and by possessing its receptors on macrophages and $\mathrm{T}$ lymphocytes results in activation of immune cells. It is a precursor of protein 
proopiomelanocortin (POMC), synthesized and stored in the anterior pituitary gland. POMC is a protein cleaved into Adrenocorticotrophic hormone $(\mathrm{ACTH})$, beta-endorphin and a-melanocyte stimulating hormone (MSH). POMC synthesized from pituitary in response to physiologic stressors such as postoperative pain results in release of corticotrophic releasing hormone $(\mathrm{CRH})$ from hypothalamus, when excessive accumulation of POMC, turn off hypothalamic production of $\mathrm{CRH}$ by feedback inhibition [4]. Endorphins produced in response to stress and pain during intense physical exercise, singing, chocolate consumption, meditation, yoga, pranayama, quantum healing (Body's energy healing method) such as pranic healing [1-42]. Endorphins bring about analgesia by inhibiting protein neurotransmitter of pain such as substance $\mathrm{P}$ in Peripheral nervous system, inhibiting the inhibitory neurotransmitter GABA resulting in dopamine release associated with pleasure in central nervous system, reducing stress. It reduces cortisol secretion and increase NK cell activity which is a first order defense against infection such as viral infection and cancer leading to production of IFN-Y, granzyme and opsonin. Suppression of sympathetic neuronal function and the parasympathetic neuronal functional stimulation by beta endorphin neurons results in activation of anti-inflammatory cytokines and peripheral immunity involved in inhibition of tumor growth and progression [1-3,10,15-25,42].

\section{Clinical Studies of Beta Endorphins on Different Types of Cancers}

A clinical trial showed that after injection of neural stem cell derived beta endorphin neurons in to the para-ventricular nucleus of hypothalamus for a long period in rat involved in suppression of prostate cancer induced by carcinogen. Additional clinical trial showed that after beta endorphin neurons transplantation results in prevention of carcinogen induced breast cancer progression and metastasis. After beta endorphin transplantation at an early tumor stage many tumors were healed, because of activation of innate immune cells activity (NK and macrophages) and in later advanced stages, tumor fail to progress, because of effect of beta endorphins on epithelial to mesenchymal transition. Beta endorphin cell treated animals, showed an increase in anti-inflammatory cytokines such as (IL-8, IL-12) and decrease in inflammatory cytokines (TNF- $\alpha$, IL-1 $\beta$ ) in inflammatory tumor milieu, thus inhibiting tumor growth and transformation. Inflammatory cytokines play a major role in breast cancer. Another study showed beta endorphin enhances invitro lymphokine production related to CD8 T levels, leucocyte migration inhibitory factor and enhanced cellular immunity in patients with squamous cell carcinoma of the head and neck.

Transplantation of endorphin cells result in suppression of tumor by increasing activity of innate immune cells such as NK cells, macrophages and suppressing epithelial to mesenchymal transition regulators. NK cells and macrophages are major innate immune cells and play a key role in defensive action against tumor cells, inhibiting inflammatory cytokines and increasing anti-inflammatory cytokines leads to inhibiting cancer growth and transformation seen in studies on animals such as rats [2-26]. Thirty randomized clinical trials on cancer patients to study the effect of music therapy include listening to recorded music on cancer patients have shown anxiety reduction by cortisol suppression, mood improvement and blood pressure reduction. It is also acts on mental health and immune function in patients with cancer by emotional expression, social support and benefit finding [30,31,34,35,42].
Studies have shown that yoga, intense physical exercise, meditation, acupuncture, dark chocolate consumption, singing, dancing improves the psychological status by reducing stress, increases social bonding by oxytocin release, physical status, increase immune cells and their activity such as macrophages, NK cells, T and B lymphocytes by beta endorphins release in patients with cancers, lead to lowering inflammation, cellular function enhancement, improves health outcome, later results in better prognosis [1,16-24,27,29,30-44].

\section{Future Challenges}

- Quantity of endorphins secreted by physical conditions and its effect on cancer in dose dependent manner.

- Activity of Beta endorphins on different cancer types need to be studied.

Beta endorphins have various effects on cancer as a preventive, therapeutic and palliative actions need to be studied related to prognosis.

Beta endorphins effect on different stages of cancer need to be studied thoroughly.

- Effect of Beta endorphins on stress, immune cells and its effect on cancer need to be understood.

\section{Implications}

One of the body's own defensive mechanism to combat against cancer is by beta endorphins, act as a preventive, therapeutic and palliative effect by reducing stress, pain, and activating immune cells without any side effects compare to other advanced cancer therapeutic modalities. Tranquility of mind can be obtained by yoga and meditation. Practice love, sympathy and empathy for caring patient are the ultimate treatment choice and patient faith in doctor produces endogenous opioids.

\section{Conclusion}

Endorphins are endogenous opioids secreted by anterior pituitary gland in response to certain conditions of our body. Stress is one of the important predisposing factor for cancer by releasing cortisol and catecholamine's induced inflammatory mediators such as IL-1 $\beta$, IL-6 and TNF- $\alpha$. Endorphins are natural stress buster, analgesic, euphoric and immune booster activity to combat against cancer without side effects shown in many studies compare to other modern therapeutic modalities, which is the major cause of concern at present world. It acts as a preventive, therapeutic and palliative treatment for cancer patients by activating immune cells such as (NK cells and macrophages), release of substance $\mathrm{P}$ and dopamine, need to be considered for future therapeutic and prognostic purpose.

\section{References}

1. Sedlmeir P, Eberth J, Schwar ZM, Zimmermann D, Haarig F, et al. (2012) The psychological effects of meditations: A meta-analysis. Psychol Bull 138: 1139-1171.

2. Dipak KS, Sengottuvelan M, Changqing Z, Nadka B (2012) Regulation of cancer progression by Beta-endorphin neuron. Cancer Res 72: 836-840.

3. Zhang C, Murugan S, Boyadjieva N, Jabbar S, Shrivastava P, et al. (2015) Beta endorphin cell therapy for cancer prevention. Cancer prev Res (Phila) 8: 56-67. 
4. Reiche EM, Nunes SO, Morimoto HK (2004) Stress, depression, the immune system and cancer. Lancet Oncol 5: 617-625.

5. Moreno-smith M, Lutgendorf SK, Sood AK (2010) Impact of stress on cancer metastasis. Future Oncol 6: 1863-1881.

6. Mantovani A, Sica A (2010) Macrophages, innate immunity and cancer: balance, tolerance and diversity. Curr Opin Immunol 22: 231-237.

7. Padgett DA, Glaser R (2003) How stress influences the immune response. Trends Immunol 24: 444-448.

8. Ondicova K, Mravec B (2010) Role of nervous system in cancer aetiopathogenesis. The lancet oncology 11: 596-601.

9. Batty D, Tom CR, Macbeath M, Stamatakis E, Kivimaki M (2017) Psychological distress in relation to site specific cancer mortality : pooling of unpublished data from 16 prospective cohort studies. BMJ 356: 108-118.

10. Xu XT, XU B, Song QB, Zeng H (2013) The role of neural-related factors in the metastasis of the gastrointestinal cancer. J Cancer Res Ther 3: 123-128.

11. Shrihari TG (2017) Dual role of inflammatory mediators in cancer. Ecancermedicine 11: 721-730.

12. Zhang, Chang Q (2013) Role of Beta-endorphin in control of stress and cancer progression in fetal alcohol exposed rats. Thesis 8: 13 .

13. Lennon FE, Moss J, Singleton PA (2012) The $\mu$-Opioid receptor in cancer progression: Is there a direct effect? Anesthesiology 116: 940-945.

14. Dowlati Y, Herrmann N, Swardfager W, Liu H, Sham L, et al. (2010) A meta-analysis of cytokines in major depression. Biol Psychiatry 67: 446-457.

15. Kuebler U, Zuccarella HC, Arpagaus A, Wolf JM, Farahmand F, et al. (2015) Stress induced modulation of NF-KB activation, inflammationassociated gene expression and cytokine levels in blood of healthy men. Brain Behav Immun 46: 87-95.

16. Archana S, Deepali V (2014) Endorphins: Endogenous opioid in human cells. W journal of pharmacy and pharmaceutical sciences. 4: 357-374.

17. Nuamtanung Y, Vorapongpiboon S, Thongpan A, Boonyaprasit S (2005) Effects of meditation on the T-lymphocytes, B lymphocytes, NK cells production. Kasetsart J 39: 660-665.

18. Michael FJ, Elizabeth OS, Nikola LV, Wenhui L (2011) Acupuncture may stimulate anticancer immunity via activation of natural killer cells. Evidence-Based complementary and alternative medicine 6: 1-14.

19. Arora S, BhattacharJee J (2008) Modulation of immune responses in stress by yoga. Inter J Yoga 1: 45-55.

20. Ader R, Choen N (1975) Behaviorally conditioned immunosuppression. Psychosom Med 37: 333-340.

21. Al-Hashimi M, Scott SWM, Thompson JP, Lambert DG (2013) Opioids and immune modulation : More questions than answers. $\mathrm{Br}$ J Anaesth 111: 80-88.

22. Jonsdottir IH (2000) Special feature for the olymphics: Effects of exercise on the immune system. Immunology and cell biology 78: 562-570.

23. Naghmeh H, Asradi, Michael M, Amitha K, Hewavitharana, et al. (2014) Biotransformation of beta-endorphins and possible therapeutic implications. Front pharmacology 19: 1-5.

24. Jose RI, Fernando P, Juan IR, Justo S, Maria Ld, et al. (2014) Levels of immune cells in transcendental meditation practitioners. International Journal of yoga 7: 147-151.

25. Naghmeh HA, Michael M, Amita KH, Nicholas P, Peter JC (2014) Front Biotransformation of beta- endorphin and possible therapeutic. frontiers Pharmacol 19: 1-8.
26. Saba GC (2011) The immune-endocrinal system: Hormones, receptors and endocrine function of immune cells-The packed transport theory. Advances in neuro immunebiology 1: 71-85.

27. Wong SY, Lua PL (2012) Effect of dark chocolate consumption on anxiety, depressive symptoms and health-related quality of life status among cancer patients. Health and the environment journal 3: 1-15.

28. Liang X, Liu R, Chen C, Fang Ji, Li T (2016) Opioid system modulates the immune function-A review. Transl Perioper pain med 1: 5-13.

29. Kilian KA, Miroslawa P, Karnil K, Krzysztof K (2016) AcupunctureCould it become everyday practice in oncology? Contemp oncol 20: 119-123.

30. William B (2011) The Endorphin Effect: A breakthrough strategy for holistic health and spiritual well-being. Kumph 29: 2011.

31. Bardt J, Dileo C, Grocke D, Magill L (2011) Music interventions for improving psychological and physical outcomes in cancer patients. Cochrane database syst Rev 8: 2011.

32. Kiecolt-Glaser JK, Bennet JM, Andridge R, Peng J, Shapiro CL, et al. (2014) Yoga's impact on inflammation, mood and fatigue in breast cancer survivors; A randomized controlled trial. J Clin Oncol 32: 1040-1049.

33. Fancourt D, Aufegger L, Williamon A (2015) Low stress and high stress singing have contrasting effects on glucocorticoid response. Front Psychol 6: $1242-1232$.

34. Dahl J, Ormstad H, Aass HCD, Malt UF, Bendz LT, et al. (2014) The plasma levels of various cytokines increased during ongoing depression and are reduced to normal levels after recovery. Psychoneuro Endocrinol 45: 77-86.

35. Olff M, Frijling JL, Kubzansky LD, Bradley B, Ellenbogen MA, et al. (2013) The role of oxytocin in social bonding, stress regulation and mental health: An update on the moderating effects of content and inter individual differences. Psychoneuro endocrinology 38: 1883-1894.

36. Green MC, Donald P, Connell M, Lutgendorf SK (2013) Psychoneuroimmunology and cancer: A cancer decade of discovery, paradigm shifts, and methodological innovations. Brain Behav Immun Suppl 30: 1-9.

37. Fancourt D, Aaron W, Carvalho L, Steptoe A, Rosie D, et al. (2016) Singing modulates mood, stress, cortisol, cytokine and neuropeptide activity in cancer patients and carers. E cancer 10: 631-638.

38. Sengottuvelan M, Nadka B, Dipak KS (2014) Protective effects of hypothalamic beta endorphin neurons against alcohol-induced liver injuries and liver cancer in rat animal models. Pathology, immunology and development 38: 2988-2997.

39. Musial F, Bussing A, Hellsser P, Choi KE, Ostermann T (2011) Mindfullness-based stress reduction for intergrative cancer careSummary of evidence. Forsch Komplement med 18: 192-202.

40. Gurbuz A, Filiz O (2005) Commentary: Dance as a therapy for cancer prevention. Asian pacific J Cancer prev 6: 408-411.

41. Nani M, Irwin MR, Chung M, Wang C (2014) The effect of mind-body therapies on the immune system-Meta analysis. PLos One 9: 10-24.

42. Priyadarshini S, Palok A (2012) Effects of psychological stress on innate immunity and metabolism in humans: A systematic analysis. Plos One 7: 8-15.

43. Adam SPB, Smith G, Sugai d, Parsa FD (2010) Understanding endorphins and their importance in pain management. Hawaii Med J 69: 70-71.

44. Fancourt D, Ockelford A, Belai A (2014) The psychoneuro immunological effects of music : A systematic review and a new model. Brain Behav Immun 36: 15-26. 